\title{
Cloning and expression of UDP-glucose: flavonoid 3-O-glucosyltransferase gene in peach flowers
}

\author{
X.C. Wen ${ }^{1}$, J. Han ${ }^{1}$, X.P. Leng ${ }^{1}$, R.J. Ma ${ }^{2}$, W.B. Jiang ${ }^{1}$ and J.G. Fang ${ }^{1}$ \\ ${ }^{1}$ College of Horticulture, Nanjing Agricultural University, Nanjing, China \\ ${ }^{2}$ Institute of Horticulture, Jiangsu Academy of Agricultural Sciences, \\ Nanjing, China \\ Corresponding author: W.B. Jiang \\ E-mail: weibingj@sohu.com
}

Genet. Mol. Res. 13 (4): 10067-10075 (2014)

Received August 1, 2013

Accepted September 9, 2014

Published December 4, 2014

DOI http://dx.doi.org/10.4238/2014.December.4.1

\begin{abstract}
To elucidate the connection between flower coloration and the expression of genes associated with anthocyanin biosynthesis, a gene encoding UDP-glucose: flavonoid 3-O-glucosyltransferase (UFGT) was isolated, and the expression of the last four genes in the anthocyanin biosynthetic pathway during peach flower development was determined. The nucleotide sequence of the peach UFGT (GenBank accession No. JX149550) is highly similar to its homologs in other plants. Total anthocyanin content initially increased during peach flower development, and then decreased over time. Expression of the four anthocyanin biosynthesis genes increased until the fullbloom stage, and then decreased during late florescence. Expression of $F 3 H, D F R$, and $U F G T$ increased dramatically at the full-bloom stage, coinciding with an increase in anthocyanin concentration. The UFGT gene may not be the only gene of the anthocyanin pathway to be differentially controlled in red peach flower tissues. Further studies are needed to genetically and physiologically characterize these genes
\end{abstract}


and enzymes in peach flowers and to gain a better understanding of their functions and relationships with flower coloration.

Key words: Peach flower; Coloration; Anthocyanin; Cloning; Gene expression

\section{INTRODUCTION}

Color formation in flowers is primarily due to accumulation of secondary metabolites such as anthocyanin, carotenoid, and betalain within the epidermal cells of plants (Mol et al., 1998). Anthocyanins are water-soluble flavonoids that form one of the main pigments in flowers and accumulate in the vacuoles of epidermal cells or anthocyanoplasts in flower petals (Harborne and Williams, 1998, 2001; Suzuki et al., 2000; Williams and Grayer, 2004; Grotewold, 2006). Other pigments, such as flavonols, carotenoids, and metal complexes, and factors, such as vacuolar $\mathrm{pH}$ and cell shape, influence the final flower pigmentation phenotype (Holton and Cornish, 1995; Katsumoto et al., 2007). Six major anthocyanidins commonly found in plants are classified according to the number and position of hydroxyl groups on the flavan nucleus: pelargonidin, cyanidin, delphinidin, peonidin, malvidin, and petunidin. The anthocyanin biosynthetic pathway has been well characterized (Forkmann, 1991; Holton and Cornish, 1995) and includes flavanone 3-hydroxylase (F3H), dihydroflavonol 4-reductase (DFR), leucoanthocyanidin dioxygenase (LDOX also called anthocyanidin synthase) (Boss and Davies, 2009), and UDP-glucose: flavonoid 3-O-glucosyltransferase (UFGT), all of which are involved in the formation of colored anthocyanidins. Anthocyanins are predominantly synthesized during petal development, and the expression of anthocyanin biosynthetic enzymes increases during flower color formation (Jackson et al., 1992).

UFGT catalyzes transfer of the glucosyl moiety from UDP-glucose to the 3-hydroxyl group of anthocyanidins, and this glycosylation step is the key to their stability (Yoshihara et al., 2005). The expression of the gene encoding UFGT has been consistently associated with pigmented anthocyanins in plants, with UFGT accumulating in the berry skins of all red grape cultivars but not in white cultivars, while the transcripts of other anthocyanin biosynthesis genes involved accumulate in both white and red cultivars (Kobayashi et al., 2001). In sweet orange, UFGT transcripts are detected in the juice vesicles of blood oranges, but not in blonde oranges (Lo Piero et al., 2005; Cotroneo et al., 2006). Thus, UFGT plays an important role in color formation in several plants. Although genetic regulation of pigmentation has been studied in the flowers of Phalaenopsis (Chen et al., 2011), Freesia hybrida (Sui et al., 2011), Petunia hybrida (Yamazaki et al., 2002), and Iris hollandica (Yoshihara et al., 2005), molecular characterization of peach flower color development lags behind that of other flower crops.

\section{MATERIAL AND METHODS}

\section{Plant materials}

Flowers from three peach cultivars ('Jingmi', 'Chunlei', and 'Red-leaf peach') were 
collected from an experimental orchard at the Horticulture Research Institute, Jiangsu Academy of Agricultural Sciences (China). The flowers of each cultivar at the flowering initiation (Stage I), full-bloom (Stage F), and late florescence (Stage L) stages were sampled (Figure 1), rapidly frozen in liquid nitrogen, and stored at $-80^{\circ} \mathrm{C}$.
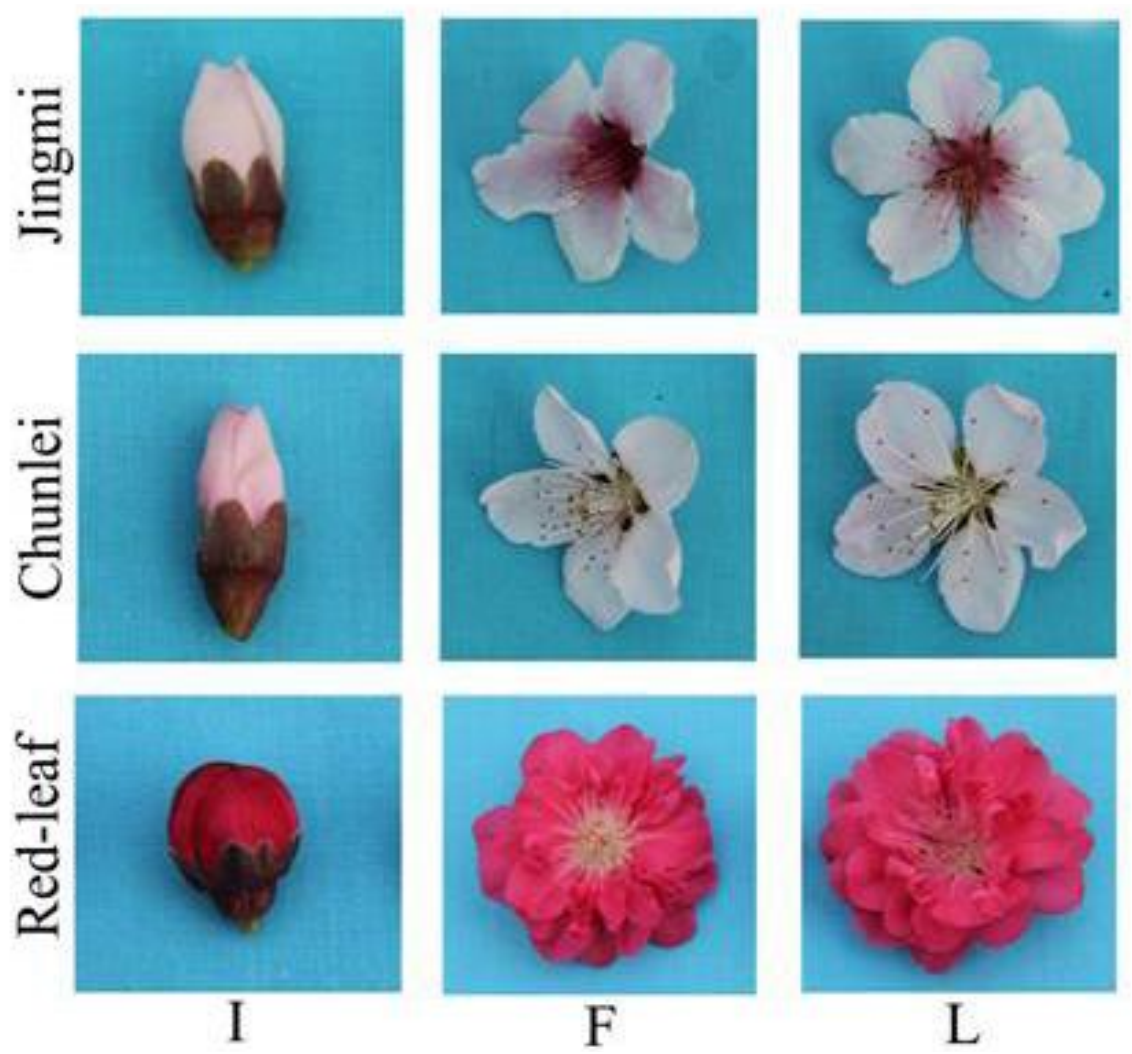

Figure 1. Pictures of three cultivars during peach flower development. Stages I, F and L: the initial time of flowering, the full-bloom stage, and the late florescence, respectively.

\section{Total RNA extraction, purification, and cDNA synthesis}

Total RNA was isolated from the peach flowers with an improved SDS method (Zhang et al., 2010). RNA was treated with DNase I (TaKaRa) according to the manufacturer protocol to remove contamination by genomic DNA. An aliquot of RNA was quantified spectrophotometrically and separated by electrophoresis on a $0.8 \%$ agarose gel to determine sample integrity. Total RNA samples $(1.0 \mu \mathrm{g})$ from different tissues were reverse-transcribed using the Fermentas RevertAid ${ }^{\mathrm{TM}}$ First-Strand cDNA Synthesis Kit with $1.0 \mu \mathrm{L}$ oligonucleotide dT primer and $1.0 \mu \mathrm{L}$ reverse transcriptase according to manufacturer protocols. All cDNA samples were diluted 10 -fold with RNase-free water and stored at $-20^{\circ} \mathrm{C}$ before use as a template in cloning and quantitative real-time PCR (qRT-PCR) experiments. 


\section{Cloning the $U F G T$ gene}

Only cDNA reverse transcribed from the fruit was used for initial cloning of $P p U F G T$. The corresponding Prunus avium UFGT full-length cDNA sequences [National Center for Biotechnology Information (NCBI), http://www.ncbi.nlm.nih.gov/guide, GenBank accession No. GU990530.1] were used as querying probes to perform blast searches of the NCBI database and the Prunus persica genomic database of The Genome Database for Rosaceae. The predicted CDS of this gene in peach (ppa005162m) was highly homologous to the gene in $P$. avium. Based on the predicted CDS sequences of UFGT in peach, specific primers (Table 1) were designed using the Primer 5.0 Software and synthesized by Invitrogen Biotechnology (Shanghai, China).

\begin{tabular}{|c|c|c|c|c|}
\hline Gene name & Start and end of sequence & Sequence (5'-3') & Product size (bp) & $\operatorname{Tm}\left({ }^{\circ} \mathrm{C}\right)$ \\
\hline \multirow[t]{7}{*}{$P p U F G T$} & $1-438$ & $\begin{array}{l}\text { ATGGCACCACAACCGA } \\
\text { AAGAGGGAGCCAAGGGAC }\end{array}$ & 438 & 55.1 \\
\hline & $427-868$ & TGGCTCCCTCTTTGGCTCTC & 442 & 58.6 \\
\hline & & ATGCCGCCTTTTGTTTGTC & & \\
\hline & $452-1341$ & TGGGAATGCCCTGATTTTTT & 890 & 56.1 \\
\hline & & TCTGCCTGTGCTGCTGTGAC & & \\
\hline & 3' & TCGGGGTCACTGTTGAGGATG & 363 & 62.6 \\
\hline & QR16326 & GGTGGTAGAGCTCGCAGGACTGCAGCTGACTG & & \\
\hline
\end{tabular}

PCR was performed in $25-\mu \mathrm{L}$ reaction volumes containing $2.5 \mu \mathrm{L}$ 10X PCR buffer, $2.5 \mu \mathrm{L} 2.5 \mathrm{mM}$ dNTP mixture, $1.5 \mu \mathrm{L} \mathrm{MgCl}_{2}, 0.2 \mu \mathrm{L} 5 \mathrm{U} / \mu \mathrm{L}$ Ex Taq polymerase (TaKaRa), $2.0 \mu \mathrm{L}$ cDNA, $1.0 \mu \mathrm{L}$ of each gene-specific primer, and $14.3 \mu \mathrm{L}$ RNase-free water. PCR was performed in an Eppendorf Authorized Thermal Cycler using the following program: $94^{\circ} \mathrm{C}$ pre-denaturing for $5 \mathrm{~min}$, followed by 38 cycles of $94^{\circ} \mathrm{C}$ for $1 \mathrm{~min}$, annealing temperature for $1 \mathrm{~min}$ (annealing temperatures are shown in Table 1 ), $72^{\circ} \mathrm{C}$ for $1 \mathrm{~min}$, and $72^{\circ} \mathrm{C}$ for $10 \mathrm{~min}$. The PCR products were separated by 1.0 to $2.0 \%$ agarose gel electrophoresis and visualized by staining with ethidium bromide. The target DNA fragment was purified with the Axyprep DNA Gel Extraction Kit (Aygen Biosciences, USA), then ligated into pMD18-T and transformed into Escherichia coli JM 109. Positive clones were identified by PCR and sequenced by Invitrogen Biotechnology (Shanghai, China).

\section{Expression of $F 3 H, D F R, L D O X$, and $U F G T$ during peach flower development}

The UFGT-specific primers for qRT-PCR amplification were designed based on the cloned sequences (ORF and one partial cDNA) using the Primer 5.0 Software. The primers for $F 3 H, D F R$, and $L D O X$ were designed based on the reported sequences (GenBank accession Nos.: HM543570.1, HM543571.1, HM543572.1). Amplicon lengths were optimized to 100 to $200 \mathrm{bp}$ to ensure optimal polymerization efficiency and minimize the impact of RNA integrity on relative quantification of gene expression. The primers were used to query the predicted peach genome database with BLASTn to confirm the identity of these genes. Before qRTPCR, each primer pair was tested by standard RT-PCR and electrophoresis on ethidium bromide-stained $2.0 \%$ agarose gels to verify amplicon size and specificity. The amplified bands 
were cloned and sequenced to confirm that they were indeed fragments of the genes targeted. The 18S rRNA sequences were used as reference genes according to the guidelines published by Bustin et al. (2009). The primer sequences, amplicon sizes, and melting temperatures for each gene and all PCR products are listed in Table 2.

\begin{tabular}{|c|c|c|c|}
\hline Name of gene & Sequence $\left(5^{\prime}-3^{\prime}\right)$ & Product size (bp) & $\operatorname{Tm}\left({ }^{\circ} \mathrm{C}\right)$ \\
\hline$P p F 3 H$ & $\begin{array}{l}\text { GGAGCAACAATTGCAGGACT } \\
\text { CATCCACTGGCTAAGCACAT }\end{array}$ & 154 & 60.1 \\
\hline$P p D F R$ & $\begin{array}{l}\text { TGAGAAACATGAGGCTGACG } \\
\text { TAACAGCCAACCGGAAAAAC }\end{array}$ & 156 & 59.8 \\
\hline$P p L D O X$ & $\begin{array}{l}\text { GACTGAGCCGCCAATCTTCC } \\
\text { TCAACAAAGCAGGTAGACAGTAGC }\end{array}$ & 225 & 61.9 \\
\hline$P p U F G T$ & $\begin{array}{l}\text { CGTCAAACTACTCGCACGAC } \\
\text { GTGAAGTGCAGCTCGGCTAT }\end{array}$ & 148 & 60.5 \\
\hline $18 \mathrm{~s}$ & $\begin{array}{l}\text { TAGTTGGTGGAGCGATTTGTCTG } \\
\text { CTAAGCGGCATAGTCCCTCTAAG }\end{array}$ & 114 & 60.0 \\
\hline
\end{tabular}

\section{qRT-PCR with SYBR green}

qRT-PCR was performed using a My-IQ 2 (Bio-Rad, USA) and SYBR Premix Ex Taq (TaKaRa, Dalian, China). qRT-PCR was performed in a $20-\mu \mathrm{L}$ volume containing 1.5 $\mu \mathrm{L}$ diluted cDNA, $0.4 \mu \mathrm{L}$ of each primer, $10.0 \mu \mathrm{L}$ Master Mix, and 7.7 $\mu \mathrm{L}$ RNase-free water. Thermo cycling conditions included an initial polymerase activation step for 2 min at $95^{\circ} \mathrm{C}$, followed by 40 cycles of $15 \mathrm{~s}$ at $95^{\circ} \mathrm{C}$ for template denaturation, $15 \mathrm{~s}$ at $60^{\circ} \mathrm{C}$ for annealing, and $20 \mathrm{~s}$ at $72^{\circ} \mathrm{C}$ for extension and fluorescence measurement. Each assay was replicated three times with the replicates corresponding to the tissue samples from the three plots in the orchard. Raw fluorescence data from the My-IQ 2 detection system were exported to Microsoft Excel and relative quantification expression levels of the four genes were calculated using the $2^{-\Delta \Delta C T}$ method (Livak and Schmittgen, 2001).

\section{Extraction and analysis of anthocyanins}

Extraction and determination of anthocyanin concentrations were according to the methods of $\mathrm{Hu}$ et al. (2011). Fresh materials $(0.2 \mathrm{~g})$ were ground and steeped in $20 \mathrm{~mL} 0.1 \%$ $\mathrm{HCl}$ methanol for $5 \mathrm{~h}$, then centrifuged at 10,000 rpm for $10 \mathrm{~min}$. Anthocyanin concentrations in the supernatants were determined by absorbance at 530 and $650 \mathrm{~nm}$, calculated using the formula: $\mathrm{Q}=0.1 \times\left(\mathrm{A}_{530}-0.25 \times \mathrm{A}_{650}\right) / 0.462(\mathrm{mg} / \mathrm{g} \mathrm{FW})$.

\section{RESULTS}

\section{Cloning of full-length PpUFGT}

The fragments of each gene cloned from flower petal-derived cDNA were spliced together using the BioXM software (Version 2.6), resulting in a 1579-nt cDNA with a fulllength ORF (1425 bp) encoding a protein of 474 amino acids. The cloned sequence was BLAST searched against the NCBI database. BLAST results for PpUFGT revealed the high- 
est identity (76\%) with a gene expressed in the fruit skin of Malus $x$ domestica (accession No. AB461385.1) and Pyrus communis (accession No. GQ325589.1).

\section{Expression analysis of four genes related to the anthocyanin biosynthetic pathway}

qRT-PCR was used to quantify expression of four genes related to anthocyanin biosynthesis throughout peach flower development. The relative expression levels of these genes in 'Jingmi', 'Chunlei', and 'Red-leaf peach' followed a similar trend. In these peach cultivars, gene expression strongly increased at stage $\mathrm{F}$, then decreased at stage $\mathrm{L}$. The levels at stages $\mathrm{F}$ and $\mathrm{L}$ were higher than at stage I (Figure 2). Generally, UFGT expression was high in 'Red-leaf peach', moderate in 'Chunlei', and low in 'Jingmi', concomitant with the anthocyanin content in these cultivars, especially during the last two stages. $F 3 H$ and $D F R$ expression followed the same pattern as UFGT. While the expression of $L D O X$ was high in 'Chunlei', moderate in 'Jingmi', and low in 'Red-leaf peach', all levels were much lower those of the other three genes at the last two stages.
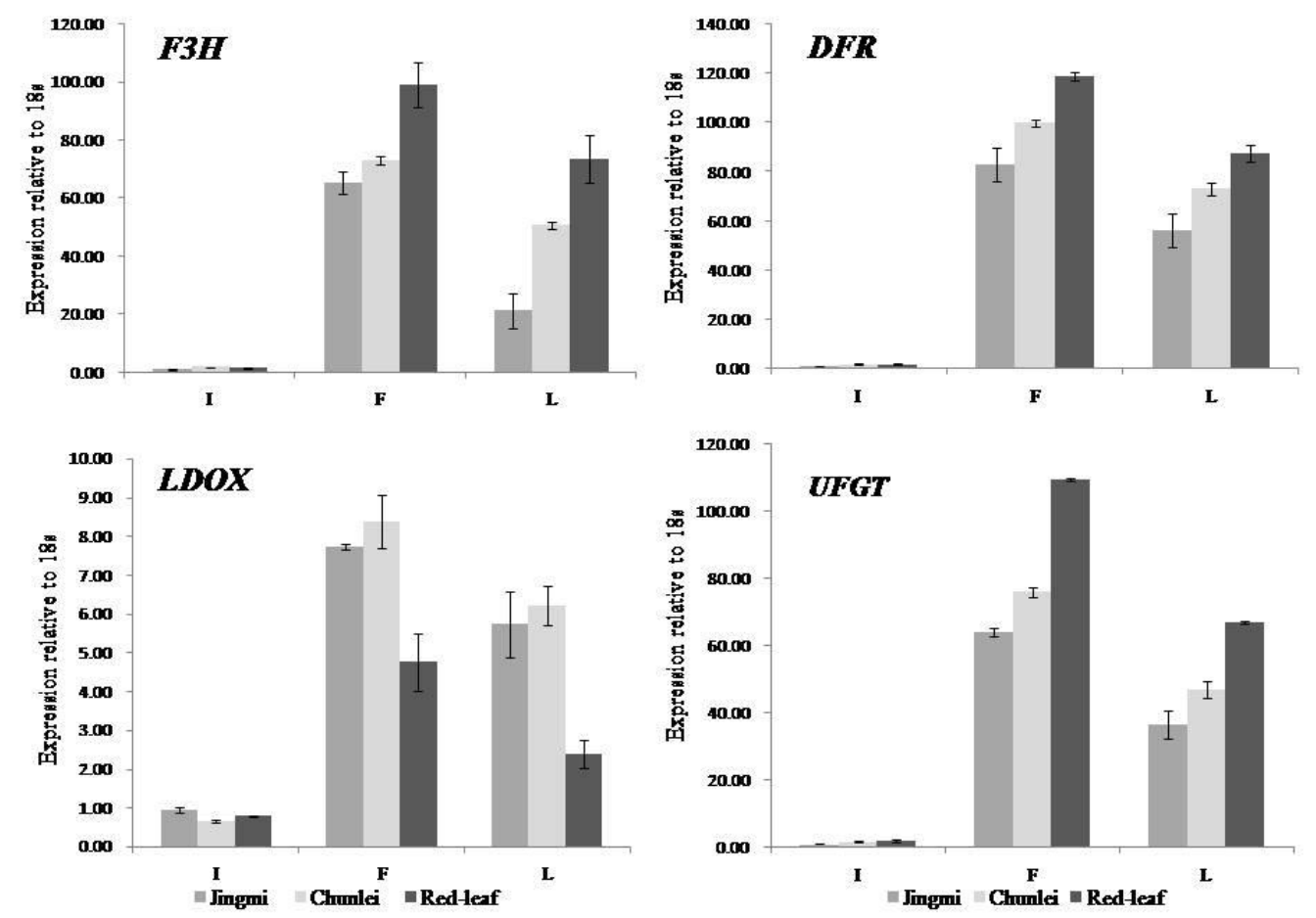

Figure 2. Expression levels of the four genes $(F 3 H, D F R, L D O X, U F G T)$ in peach flowers at three different stages of 'Jingmi', 'Chunlei' and 'Red-leaf peach'.

Relationship between flower color, anthocyanin accumulation, and transcriptional activity of related genes

The total anthocyanin content during peach flower development increased, followed 
by a decrease as the flowers matured (Figure 3). At stage F, the anthocyanin content in the peach flowers of the three cultivars increased significantly in comparison to stage I. In each stage, the anthocyanin content of 'Red-leaf peach' was clearly higher than that of 'Chunlei' and 'Jingmi'. Photographs of the flowers of these cultivars during flower development (Figure 1) suggest the total anthocyanin content is directly proportional to flower color intensity.

The expression of all four genes $(F 3 H, D F R, L D O X, U F G T)$ was high at stage $\mathrm{F}$, moderate at stage $\mathrm{L}$, and low at stage I. There was a strong positive correlation between $F 3 H, D F R$, and $U F G T$ expression and anthocyanin content. At the last two stages of flower development, the expression of $F 3 H, D F R$, and $U F G T$ in 'Red-leaf peach' (deep-red cultivar) were significantly higher than in 'Chunlei' (pale-red cultivar) and 'Jingmi' (pale-red cultivar). The expression of $L D O X$ differed from the other three genes; when this observation is considered with the differences in total anthocyanin content in the three cultivars, we conclude that unlike $F 3 H$, $D F R$, and $U F G T$, the $L D O X$ gene has no direct impact on color formation in peach flowers.

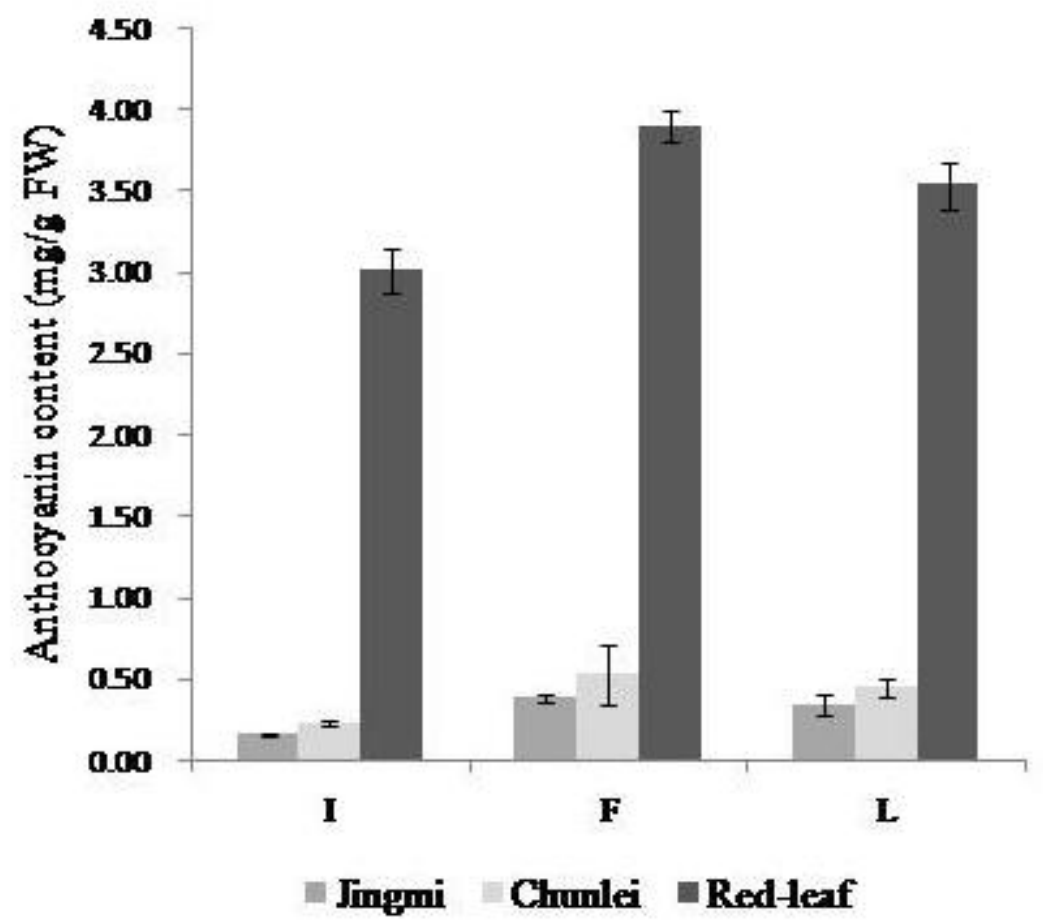

Figure 3. Total anthocyanin contents of three cultivars during peach flower development.

\section{DISCUSSION}

Anthocyanins, forming the largest subclass of plant flavonoids, are the main pigments that contribute to flower coloration. The results of this study confirm that anthocyanin content is also the major determinant of the red color in peach flowers (Figure 1; Figure 3). Transcript levels of $F 3 H, D F R, L D O X$, and $U F G T$ in the flowers of the three sampled cultivars 
peaked synchronously with the anthocyanin content in the red flowers of these cultivars at stage F (Figure 2), strongly indicating that the expression of anthocyanin biosynthesis genes correlates with flower color development. It has been similarly established that the four genes related to anthocyanin biosynthesis are coordinately expressed during fruit development and their levels of expression in peach fruit skins are positively correlated to the degree of red coloration (Tomomi, 2004). Several studies suggest a positive correlation in the expression of genes involved in anthocyanin biosynthesis including $L D O X$ and $U F G T$, and anthocyanin content (Honda et al., 2002; Ubi et al., 2006). In the flowers of Phalaenopsis, the expression of these genes is thought to influence flower color formation, and UFGT may be the key enzyme for coloring in orchid flowers (Chen et al., 2011). In our study, the expression of all four genes increased at stage $\mathrm{F}$, and then decreased at stage L, concomitant with anthocyanin content; expression of $F 3 H, D F R$, and $U F G T$ showed a particularly sharp increase at the full-bloom stage when the anthocyanin concentration was highest. In contrast, this rise in the level of $L D O X$ was not evident in the three peach cultivars (Figure 2), indicating that this gene may not be directly related to anthocyanin biosynthesis. Our results clearly show that UFGT may not be the only gene in the anthocyanin pathway to be differentially controlled in red peach flower tissues.

In summary, a full-length cDNA encoding the UFGT protein was isolated from P. persica and its functional characterization was confirmed. This study supports additional research on the mechanisms of peach flower coloration and lays a foundation for the development of strategies for changing flower pigmentation through genetic engineering. The fact that regulation of the anthocyanin biosynthesis pathway varies in different plant tissues should prompt wider studies to determine whole plant behavior of the genes involved in this pathway in peach.

\section{ACKNOWLEDGMENTS}

Research supported by the National Natural Science Foundation of China (\#31101517) and the Science and Technology Innovation Foundation of Nanjing Agricultural University Young Teachers (\#KJ09010).

\section{REFERENCES}

Boss PK and Davies C (2009). Molecular Biology of Anthocyanin Accumulation in Grape Berries. In: Grapevine Molecular Physiology \& Biotechnology (Roubelakis-Angelakis KA, ed.). 2nd ed. Springer Science \& Business Media B.V., Glen Osmond, 263-292.

Bustin SA, Benes V, Garson JA, Hellemans J, et al. (2009). The MIQE guidelines: minimum information for publication of quantitative real-time PCR experiments. Clin. Chem. 55: 611-622.

Chen WH, Hsu CY, Cheng HY, Chang, et al. (2011). Downregulation of putative UDP-glucose: flavonoid 3-0-glycosyltransferase gene alters flower coloring in Phalaenopsis. Plant Cell Rep. 30: 1007-1017.

Cotroneo PS, Russo MP, Ciuni M and Recupero GR (2006). Quantitative real-time reverse transcriptase-PCR profiling of anthocyanin biosynthetic genes during orange fruit ripening. J. Am. Soc. Hortic. Sci. 131: 537-543.

Forkmann G (1991). Flavonoids as flower pigments: the formation of the natural spectrum and its extension by genetic engineering. Plant Breed. 106: 1-26.

Grotewold E (2006). The genetics and biochemistry of floral pigments. Annu. Rev. Plant Biol. 57: 761-780.

Harborne JB and Williams CA (1998). Anthocyanins and other flavonoids. Nat. Prod. Rep. 15: 631-652.

Harborne JB and Williams CA (2001). Anthocyanins and other flavonoids. Nat. Prod. Rep. 18: 310-333.

Holton TA and Cornish EC (1995). Genetics and biochemistry of anthocyanin biosynthesis. Plant Cell 7: 1071-1083.

Honda C, Kotoda N, Wada M, Kondo S, et al. (2002). Anthocyanin biosynthetic genes are coordinately expressed during red coloration in apple skin. Plant Physiol. Biochem. 40: 955-962. 
Hu C, Gong Y, Jin S and Zhu Q (2011). Molecular analysis of a UDP-glucose: flavonoid 3-O-glucosyltransferase (UFGT) gene from purple potato (Solanum tuberosum). Mol. Biol. Rep. 38: 561-567.

Jackson D, Roberts K and Martin C (1992). Temporal and spatial control of expression of anthocyanin biosynthetic genes in developing flowers of Antirrhinum majus. Plant J. 2: 425-434.

Katsumoto Y, Fukuchi-Mizutani M, Fukui Y, Brugliera F, et al. (2007). Engineering of the rose flavonoid biosynthetic pathway successfully generated blue-hued flowers accumulating delphinidin. Plant Cell Physiol. 48: 1589-1600.

Kobayashi S, Ishimaru M, Ding CK, Yakushiji H, et al. (2001). Comparison of UDP-glucose:flavonoid 3-O-glucosyltransferase (UFGT) gene sequences between white grapes (Vitis vinifera) and their sports with red skin. Plant Sci. 160: 543-550.

Livak KJ and Schmittgen TD (2001). Analysis of relative gene expression data using real-time quantitative PCR and the 2(-Delta Delta C(T)) method. Methods 25: 402-408.

Lo Piero AR, Consoli A, Puglisi I, Orestano G, et al. (2005). Anthocyaninless cultivars of sweet orange lack to express the UDP-glucose flavonoid 3-O-glucosyl transferase. J. Plant Biochem. Biotechnol. 14: 9-14.

Mol J, Grotewold E and Koes R (1998). How genes paint flowers and seeds. Trends Plant Sci. 3: 212-217.

Sui X, Gao X, Ao M, Wang QM, et al. (2011). cDNA cloning and characterization of UDP-glucose:anthocyanidin 3-O-glucosyltransferase in Freesia hybrida. Plant Cell Rep. 30: 1209-1218.

Suzuki KI, Xue HM, Tanaka Y, Fukui Y, et al. (2000). Flower color modifications of Torenia hybrida by cosuppression of anthocyanin biosynthesis genes. Mol. Breed. 6: 239-246.

Tomomi T (2004). Expression of anthocyanin biosynthesis genes in the skin of peach and nectarine fruit. J. Am. Soc. Hortic. Sci. 129: 857-862.

Ubi BE, Honda C, Bessho H, Kondo S, et al. (2006). Expression analysis of anthocyanin biosynthetic genes in apple skin: EVect of UV-B and temperature. Plant Sci. 170: 571-578.

Williams CA and Grayer RJ (2004). Anthocyanins and other flavonoids. Nat. Prod. Rep. 21: 539-573.

Yamazaki M, Yamagishi E, Gong Z, Fukuchi-Mizutani M, et al. (2002). Two flavonoid glucosyltransferases from Petunia hybrida: molecular cloning, biochemical properties and developmentally regulated expression. Plant Mol. Biol. 48: 401-411.

Yoshihara N, Imayama T, Fukuchi-Mizutanic M, Okuhara H, et al. (2005). cDNA cloning and characterization of UDPglucose: anthocyanidin 3-O-glucosyltransferase in Iris hollandica. Plant Sci. 169: 496-501.

Zhang YP, Wang C, Yu HP, Cai BH, et al. (2010). Screening of RNA extraction methods for various grapevine organs and tissues. Acta Agric. Boreali-Sinica 19: 135-140. 